Check for updates

Cite this: J. Mater. Chem. A, 2020, 8 , 7935

Received 2nd December 2019

Accepted 1st April 2020

DOI: 10.1039/c9ta13182e

rsc.li/materials-a

\section{Transparent lignin-containing wood nanofiber films with UV-blocking, oxygen barrier, and anti- microbial properties $\uparrow$}

\author{
Juho Antti Sirviö, (D) *a Mostafa Y. Ismail, ${ }^{a}$ Kaitao Zhang, ${ }^{a}$ Mysore V. Tejesvi ${ }^{\text {bc }}$ \\ and Ari Ämmälä iD a
}

\begin{abstract}
Lignocellulose is a potential raw material for film and membrane applications, such as packaging for every day consumables or a supporting barrier layer for flexible electronics. Here, lignin-containing cationic wood nanofiber (CWNF) films were produced using sawdust as the starting material. Sawdust was directly cationized using four different aqueous solvents containing tetraethylammonium hydroxide with different carbamides (urea, methylurea, ethylurea, or dimethylurea) and glycidyltrimethylammonium chloride as the cationization agent. Cationic wood was obtained with a high cationic group content (around $1.5 \mathrm{mmol} \mathrm{g}^{-1}$ ) and yield (89-100\%), and CWNFs were easily obtained by mechanical disintegration as a water suspension. The films produced using solvent-casting exhibited excellent visible-light transparence (around $80 \%$ at $600 \mathrm{~nm}$ ), and the presence of lignin allowed high UVadsorption (below $380 \mathrm{~nm}$, transmittance was under 1\%). The films showed high oxygen barrier properties (below 400 and $4000 \mathrm{~m}^{3} \mu \mathrm{m} / \mathrm{m}^{2}$ day atm at a relative humidity of 50 and $92 \%$, respectively) and good mechanical strength. An antimicrobial test conducted using the disk method showed that the CWNF films exhibited bacterial anti-adhesive properties with a small inhibition zone. CWNFs are therefore potential environmentally friendly packaging materials to prevent food spoilage, or useful as a UV-absorption layer for electronic devices such as solar cells.
\end{abstract}

\section{Introduction}

Films and membranes have become a part of everyday life as they are used in common items such as food packaging and electronics (e.g. in displays and flexible electronics). The majority of current films and membranes on the market are produced from oil-derived polymeric materials and plastics due to their inexpensive production and durability. ${ }^{1}$ However, there is a growing concern about the use of plastics in packaging due to their severe environmental impact. Significant amounts of oil-based plastics are non-biodegradable, that is, persist in nature for long periods, causing negative impacts on the environment. ${ }^{2}$ Although some of these plastics can be recycled, current recycling efforts are not sufficient to prevent the pollution. ${ }^{3}$ There is also concern about the contamination of recycled plastics, which reduces their safety in use for food packaging. ${ }^{4}$

\footnotetext{
${ }^{a}$ Fibre and Particle Engineering Research Unit, University of Oulu, P. O. Box 4300, 90014 Oulu, Finland. E-mail: juho.sirvio@oulu.fi

${ }^{b}$ Department of Ecology and Genetics, University of Oulu, Oulu, Finland

${ }^{c}$ CHAIN Antimicrobials LLC, Teknologiantie 2, Oulu, 90590, Finland

$\dagger$ Electronic supplementary information (ESI) available: Additional DRIFT spectra and TEM images; photographs of CWNF solutions and films, and antimicrobial performance of the reference film; histograms; stress-strain curves. See DOI: 10.1039/c9ta13182e
}

In addition, some of the starting materials (i.e. monomers) of synthetic polymers are toxic, which can cause issues during material synthesis, and if those monomers remain in the product beyond synthesis they will also be in the final product. ${ }^{5}$

Several strategies have been developed to minimize the environmental impact of plastics. Biodegradable polymers have been produced from oil-derived chemicals and use of biomassderived monomers in polymer synthesis has gained a significant amount of interest due to concerns about the nonrenewable nature of oil resources and the toxicity of oil-based monomers. ${ }^{6-8}$ Another means to replace current plastics is the use of natural polymers as film and membrane materials. Lignocellulosic biomass is a highly abundant potential polymer source. ${ }^{9}$ The main components of lignocellulose, cellulose and lignin are the most common polysaccharide and natural aromatic polymers, respectively. ${ }^{10}$ The third main component of lignocellulose, hemicelluloses, are a class of polysaccharides with useful properties such as water solubility.

Compared to polysaccharides, lignin has certain unique properties, namely low polarity (i.e. hydrophobic characteristics), the ability to absorb ultraviolet (UV) light, and antioxidant properties. ${ }^{11}$ Due to these properties, lignin has been studied as an active component to produce film materials with decreased hydrophilicity ${ }^{12}$ and UV blocking properties. ${ }^{13}$ Cellulose fibers have been investigated to produce films and membranes in the 
form of nanosized materials (e.g. cellulose nanofibers [CNFs] and cellulose nanocrystals [CNCs]). The films produced from nanosized cellulose can exhibit high transparency typical of plastics; however, the mechanical strength of nanocellulose films can highly surpass those of synthetic materials. ${ }^{\mathbf{1 4}}$

Individualized lignin and nanocellulose have been studied to produce composite materials, such as films. ${ }^{15-17}$ However, the separation of lignin and cellulose (and hemicellulose) requires harsh reaction conditions and use of hazardous chemicals (e.g. chlorine-based bleaching chemicals). Therefore, to reduce the environmental burden and to obtain materials with the advantages of the individual components (e.g. hydrophobicity and UV-blocking traits of lignin together with the high strength of nanosized cellulose), there has been growing interest in the production of nanomaterials directly from biomass. ${ }^{18-22}$ However, due to the recalcitrant nature of the natural cellulosehemicellulose-lignin-complex, the production of nanomaterials directly from biomass can be a more cumbersome process compared to nanoparticles obtained from individual components. Several methods, such as intensive mechanical refining, ${ }^{21}$ heat-intensified grinding, ${ }^{19}$ and enzymatic treatment $^{23}$ have been studied to produce biomass-based nanomaterials, generally termed lignocellulose nanofibers or wood nanofibers (WNFs). Similar to the production of CNFs and CNCs, the introduction of charged chemical groups into biomass has been shown to improve the disintegration of biomass in its nanosized constituents ${ }^{\mathbf{2 0 , 2 4 , 2 5}}$ due to the generation of steric repulsion and improved swelling (i.e. osmotic pressure). The additional chemical groups can provide functionality to biomass-based nanomaterials which can be used, for example, in water purification. ${ }^{26}$

In this study, we investigated the production of cationic WNFs (CWNFs) from sawdust without pre-removal of wood content, in order to obtain a film material with the sufficient mechanical properties and transparency of cellulose and the UV-blocking and the humidity-resistant oxygen barrier properties of lignin. The cationic group was introduced in order to improve disintegration efficiency and to facilitate antimicrobial functionality. Chemical modification was conducted using aqueous tetraalkylammonium hydroxide (recently demonstrated as an environmentally friendly solvent for biomass ${ }^{27}$ ) in the presence of four carbamides (urea, methylurea [MU], ethylurea [EU], and 1,3-dimethylurea [DMU]). Carbamates are ideal components for solvents and reaction media due to their low toxicity and biodegradability. ${ }^{28}$

\section{Materials and methods}

\section{Materials}

Unbleached spruce sawdust was obtained in a never-dried form. The sawdust was first oven-dried $\left(24 \mathrm{~h}\right.$ at $\left.60{ }^{\circ} \mathrm{C}\right)$ and ground with an Ultra Centrifugal Mill ZM 200 (Retsch, Germany) using a sieve size of $250 \mu \mathrm{m}$. The mean particle size of the ground sawdust was $208 \mu \mathrm{m}$, as determined using a Beckman Coulter LS 13320 laser diffraction particle size analyzer. The lignin (28.6 wt\%), acetone-soluble extract (1.2 wt\%), and alkalinesoluble hemicellulose and degraded cellulose (19.7 wt\%) contents of the sawdust were analyzed using TAPPI T 222 om02, TAPPI T 280 standard pm-99, and TAPPI T 212 om-02 standards, respectively.

Tetraethylammonium hydroxide solution (TEAOH, 35 wt $\%$ in water), $N$-methylurea (MU), $N$-ethylurea (EU), and 1,3-dimethylurea (1,3-DMU) were obtained from Sigma Aldrich (Germany) and urea from Borealis Biuron (Austria). The cationization agent glycidyltrimethylammonium chloride (GTAC, $80 \mathrm{wt} \%$ in water) was obtained from TCI. Polyethylenesulfonate (PES-Na, BTG Mütek GmbH, Germany) was used as a polyelectrolyte titrant. Expect for cationization of wood, deionized water was used as the medium for all the steps. All chemicals were used as received.

\section{Cationization of wood}

Prior to cationization, carbamides (urea, 1,3-DMU, MU, or EU) were individually mixed with TEAOH at a carbamide:TEAOH molar ratio of $2: 1$ at room temperature to obtain $18 \mathrm{~g}$ of clear, colorless solvent. Then, $2 \mathrm{~g}$ of sawdust was added followed by the addition of $4.42 \mathrm{ml}$ of GTAC (the mass ratio of sawdust : GTAC was $1: 2$ ). The mixture was allowed to react at room temperature for $24 \mathrm{~h}$ while mixing. After the desired reaction, $10 \mathrm{ml}$ of water was added and the product was transferred into centrifugation tubes. The reaction vessel was carefully rinsed with water and the product (with solvent and rinsing water) was transferred into a centrifugation tube and diluted with water up to a volume of $50 \mathrm{ml}$. The mixture was centrifuged for $10 \mathrm{~min}$ using a rotation speed of $10000 \mathrm{rpm}$ at $25{ }^{\circ} \mathrm{C}$. The supernatant was carefully discarded and the sample was repeatedly diluted with water and centrifuged until the $\mathrm{pH}$ of the supernatant water was neutral, indicating the removal of highly basic reaction solvent. After this, the samples were collected and stored at $4{ }^{\circ} \mathrm{C}$ as a water suspension having a consistency of about $10 \%$.

\section{Elemental analysis of sulfated cellulose}

The nitrogen content of the oven-dried samples was analyzed using a PerkinElmer CHNS/O 2400 Series II elemental analyzer. As GTAC introduces one nitrogen per cationic group, the cationic group content is directly related to the nitrogen content.

\section{Diffuse reflectance infrared Fourier transform spectroscopy}

The chemical characterization of the original and cationic wood was performed by diffuse reflectance infrared Fourier transform (DRIFT) spectroscopy using a Bruker Vertex 80v spectrometer (USA). Spectra of the dried samples were obtained in the 600$4000 \mathrm{~cm}^{-1}$ range and 40 scans at a resolution of $2 \mathrm{~cm}^{-1}$ were taken.

\section{Disintegration of cationic wood into nanofibers}

The disintegration of cationic wood was performed with a microfluidizer (Microfluidics M-110EH-30, USA). The cationic wood suspension in water (a consistency of $0.5 \mathrm{wt} \%$ ) was passed twice at a pressure of 1000 bar through the 400 and $200 \mu \mathrm{m}$ chambers and separately once at a pressure of 1500 bar through 
the 400 and $100 \mu \mathrm{m}$ chambers of the microfluidizer (Microfluidics M-110EH-30, USA).

\section{Charge density}

The surface charge densities of the CWNFs were determined using the polyelectrolyte titration method through a particle charge detector (BTG Mütek PCD-03, Germany). $10 \mathrm{ml}$ of nanofiber suspension (at $0.01 \mathrm{wt} \%$ in water) was titrated with PES-Na ( 1 meq. $\left.\mathrm{l}^{-1}\right)$. The charge density was calculated based on the PES-Na consumption.

\section{Transmission electron microscopy}

The analysis of the size and the morphology of the CWNFs was performed by transmission electron microscopy (TEM, JEOL JEM-2200FS, Japan). The samples were first diluted to around $0.001 \mathrm{wt} \%$ and then applied on poly-L-lysine treated carbon coated copper grids. ${ }^{29} 2 \mathrm{wt} \%$ uranyl acetate was used as the staining agent. The average diameter of the nanofibers was measured using ImageJ software 1.50i.

\section{Fabrication of films}

CWNF films were fabricated using the solvent-casting method as follows: the desired amount of CWNF suspension was diluted with water to a total mass of $60 \mathrm{~g}$ and sonicated for $10 \mathrm{~min}$ in order to remove any air bubbles trapped in the suspension. After sonication, the suspension was poured on a polystyrene tray (area of $0.0147 \mathrm{~m}^{2}$ ) and the water content was allowed to evaporate at room temperature for 5 days to produce films with a grammage of $30 \mathrm{~g} \mathrm{~m}^{-2}$. The films were then stored at $50 \%$ relative humidity $(\mathrm{RH})$ for two days and then peeled off from the tray.

\section{Tensile test}

Tensile tests were conducted with a universal testing device (Instron 5544, USA). Prior to measurement, samples were conditioned at $23{ }^{\circ} \mathrm{C}$ and a humidity of $50 \%$ for 2 days. The samples were prepared by cutting films into strips at a length of $70 \mathrm{~mm}$ and a width of $5 \mathrm{~mm}$. The average thickness of the samples was measured at 3 random positions using a thickness gauge (Precision Thickness Gauge FT3, Hanatek Instrument, $\mathrm{UK}$ ). The tensile test was conducted using a $2 \mathrm{kN}$ force sensor, a gauge length of $40 \mathrm{~mm}$, and a strain speed of $5 \mathrm{~mm} \mathrm{~min} \mathrm{~mm}^{-1}$ until breaking. Five samples of each film were measured.

\section{UV-Vis spectroscopy}

The transmittance of the CWNF films was measured in the wavelength range of 200-800 $\mathrm{nm}$ using a UV-Vis spectrometer (Shimadzu, Japan). In order to ensure that the films were perpendicularly aligned against the incoming beam and to avoid wrinkling, the films were put between two quartz glass slides before being set up in a cuvette stand.

The absorption coefficient was calculated using the BeerLambert law:

$$
\frac{I}{I_{0}}=\mathrm{e}^{-\mu x}
$$

where the transmittance (ratio of transmitted $[I]$ and incoming $\left[I_{0}\right]$ flux) depends on the absorption coefficient $\mu$ and the path length of the light $x$.

\section{Oxygen barrier test}

The oxygen barrier properties of the CWNF films were investigated by measuring the oxygen transmission rate (OTR) values using a MOCON OxTran 2/20 (Minneapolis, MN). The oxygen permeability (OP) was calculated by multiplying the OTR values with the thickness of the film and dividing it by the difference in the partial pressure of the oxygen gas between the two sides of the film. During measurement, the films were exposed to $100 \%$ oxygen on one side and to oxygen-free nitrogen gas (98\% nitrogen and $2 \%$ hydrogen) on the other side. The measurements were conducted at $23{ }^{\circ} \mathrm{C}$, with a relative humidity ( $\left.\mathrm{RH}\right)$ of 50 and $92 \%$, and normal atmospheric pressure. Two individual samples from each of the films were measured.

\section{Antimicrobial test}

The antibacterial activity of the fabricated films was examined against Staphylococcus aureus (S.aureus, Gram-positive) and Escherichia coli (E.coli, Gram-negative). A mixture of MuellerHinton ( $\mathrm{MH})$ broth and agar in $500 \mathrm{ml}$ distilled water was autoclaved at $120{ }^{\circ} \mathrm{C}$ for $15 \mathrm{~min}$. After autoclaving, the mixture was cooled down to $46^{\circ} \mathrm{C}$, and then an appropriate amount of E.coli and S.aureus suspension was added into the $\mathrm{MH}$ agar and mixed, respectively, resulting in a bacterial concentration of $6 \times$

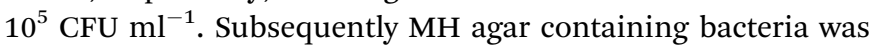
poured into Petri dishes. Square $15 \times 15 \mathrm{~mm}$ film samples were placed on the surface of $\mathrm{MH}$ agar plates and incubated at $37{ }^{\circ} \mathrm{C}$ for $24 \mathrm{~h}$. Afterwards, the halo sizes in the plates were visually observed. All the samples were analyzed in triplicate.

\section{Thermogravimetric analysis}

The thermal properties of the original sawdust and CWNF films were investigated using a thermal analyzer (Netzsch STA 449F3, Germany) under an air flow (dynamic air) at a constant rate of $60 \mathrm{ml} \mathrm{min}{ }^{-1}$. Approximately $5 \mathrm{mg}$ of dry sample was weighed in an aluminum oxide pan and heated from 30 to $950{ }^{\circ} \mathrm{C}$ at a rate of $10{ }^{\circ} \mathrm{C} \mathrm{min}^{-1}$. The first derivate curves of TGA (DTG) were recorded using OriginPro 2019 software.

\section{Statistical analysis}

One-way analysis of variance (ANOVA) was conducted using OriginPro 2019 to determine the statistical significance $(p<$ 0.05 ) of the tensile barrier test results.

\section{Results and discussion}

\section{Cationization of wood}

Previously, cationization of cellulose ${ }^{30}$ and lignin $^{31}$ with GTAC (and its parent component, 3-chloro-2hydroxypropyltrimethylammonium chloride) has been 

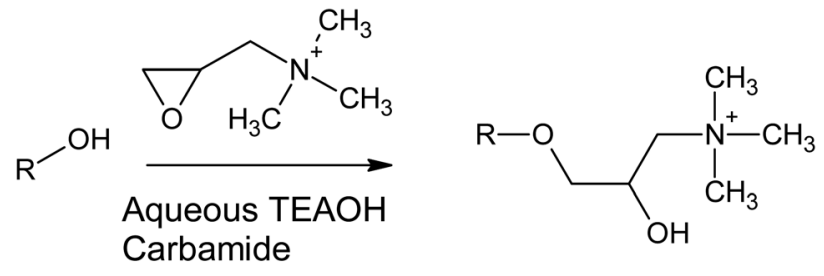

$\mathrm{R}=$ Cellulose, lignin, or hemicellulose

Scheme 1 A simplified reaction scheme of the cationization of wood. It should be noted that the hydroxyl group generated by the epoxide ring opening might also react, possibly forming a cationic side-chain in the wood structure.

conducted using alkaline aqueous solutions (Scheme 1). Alkaline conditions allow the deprotonation of the hydroxyl groups of cellulose, lignin, and hemicelluloses, making them more nucleophilic towards the epoxide ring opening reaction. In the current study, aqueous TEAOH solutions with four different carbamides (urea, MU, EU, and 1,3-DMU) were used as reaction media for wood. TEAOH together with carbamides, described as aqueous deep eutectic solvent (DES), has been previously used for room temperature dissolution of low-molecular weight microcrystalline cellulose..$^{32}$ Although the dissolution of high-molecular weight cellulose, such as that present in wood, is limited, it was assumed that TEAOH with carbamides could serve as an efficient reaction medium for wood. The wood material used here was dry sawdust, which was mildly ground to a smaller size, leaving the majority of the wood components still intact. It was assumed that a TEAOH-carbamide solution would function as a swelling agent, allowing the efficient chemical modification of the wood material, as well as providing sufficient alkalinity to enhance the reactivity of the hydroxyl groups. In addition, the TEAOH - carbamide solutions exhibit low viscosity (even as $5 \mathrm{wt} \%$ microcrystalline cellulose solutions) allowing the use of a low-weight ratio between sawdust and solvent (here $1: 9$ ), thus decreasing the consumption of the solvent.

The TEAOH-carbamide solutions were prepared using $35 \mathrm{wt} \%$ aqueous TEAOH solution and carbamides with a TEAOH-carbamide molar ratio of $1: 2$. Table 1 shows that the solvents gave similar results: the cationic group content and charge densities were 1.4-1.6 mmol g${ }^{-1}$ and 1.5-1.9 meq. $\mathrm{g}^{-1}$, respectively. The small variation in the cationic group content and charge density originates from the use of different analysis methods, as they are measured using elemental analysis and polyelectrolyte titration, respectively. The most apparent differences between samples was observed in the yield, as the solution containing MU or 1,3-DMU showed quantitative yields, indicating that most of the wood components are preserved after cationization. On the other hand, the yields obtained with urea and EU were around $90 \%$. These variations in the yield may originate from the different solubility of the wood components and the product in the solvents used. In addition, it is possible that the water used in the washing stage could dissolve part of the cationic wood.

The high yield shown by cationized wood is in line with previous studies, where chemically modified wood showed yields of over $90 \%{ }^{25,33}$ Previous studies have shown that the yield of chemically modified wood can be higher when compared to the corresponding cellulose samples. The higher yield of wood compared to pure cellulose may be due to the composition of the wood. In addition to cellulose, lignin and hemicellulose have reactive hydroxyl groups that most likely take part in chemical reactions, lowering the overall charge density of the individual components and making them less soluble, for example, in water during washing. Therefore, in addition to the use of a starting material with a higher production yield (e.g. wood vs. cellulose), the use of wood can give a material with an excellent yield.

In the literature, cationic CNFs have been produced using GTAC in a mixture of cellulose, water, isopropanol and alkaline salt (e.g. NaOH).$^{34}$ Other solvents have also been studied to minimize the epoxide ring opening reaction with water, which consumes the reagent and decreases the reaction efficiency. ${ }^{35,36}$ Depending on the reaction conditions (e.g. solvent content, time, and temperature), CNFs with charge densities of 0.354 (ref. 37) and 0.403 (ref. 38) meq. $\mathrm{g}^{-1}$ or a cationic group content of $0.21-1.140,{ }^{36}$ $0.59-2.31,{ }^{39}$ and 1.91 (ref. 40) $\mathrm{mmol} \mathrm{g}^{-1}$ have been reported. Chlorocholine chloride together with DMSO as a solvent was used to produce CNFs with a cationic group content of 0.09-0.19 mmol $\mathrm{g}^{-1,41}$ whereas Girard's reagent (after periodate oxidation) was used to obtain nanofibers with a charge density of 1.10-2.13 meq. $\mathrm{g}^{-1}$.42 $^{\mathrm{In}}$ addition, WNFs with a cationic group content of $0.70 \mathrm{mmol} \mathrm{g}^{-1}$ were obtained using betaine hydrochloride as a reagent and Tosyl chloride as a coupling agent in DES. ${ }^{33}$ Therefore, the current method can be seen as an efficient way to produce highly charged wood-based materials with a charge density on par with that of CNFs with the highest reported charge densities. The high cationic charge of the wood produced in this study could allow it to be used in water purification applications, for example as a flocculant, ${ }^{42,43}$ or in the removal of toxic components, such as dyes, from water. ${ }^{39,44}$

Table 1 Carbamides, nitrogen content, cationic group content, charge density, yield of cationized wood, and average width of the CWNFs produced by mechanical disintegration across four samples

\begin{tabular}{|c|c|c|c|c|c|c|}
\hline Sample & Carbamide & N (\%) & $\begin{array}{l}\text { Cationic group } \\
\text { content }\left(\mathrm{mmol} \mathrm{g}^{-1}\right)\end{array}$ & $\begin{array}{l}\text { Charge density } \\
\left(\text { meq. } \mathrm{g}^{-1}\right)\end{array}$ & Yield (\%) & $\begin{array}{l}\text { Width of CWNFs } \\
(\mathrm{nm})\end{array}$ \\
\hline 1 & Urea & $2.1 \pm 0.08$ & $1.5 \pm 0.06$ & $1.6 \pm 0.07$ & 89 & $4.8 \pm 1.3$ \\
\hline 2 & 1,3-DMU & $2.2 \pm 0.08$ & $1.6 \pm 0.06$ & $1.7 \pm 0.06$ & 100 & $3.7 \pm 0.8$ \\
\hline 3 & MU & $2.1 \pm 0.02$ & $1.5 \pm 0.02$ & $1.9 \pm 0.01$ & 100 & $3.9 \pm 1.0$ \\
\hline 4 & EU & $2.0 \pm 0.04$ & $1.4 \pm 0.03$ & $1.5 \pm 0.03$ & 91 & $4.8 \pm 1.6$ \\
\hline
\end{tabular}




\section{Chemical characterization of cationic wood}

The most distinguished chemical differences in sawdust before and after cationization are the disappearance of the ester bond (at $1738 \mathrm{~cm}^{-1}$ ) that naturally occurs in the wood (the acetyl group of hemicellulose and the ester linkage of the carboxylic groups in the ferulic and $p$-coumaric acids of lignin/hemicellulose $)^{45}$ and the appearance of a carbon-nitrogen stretching band at $1483 \mathrm{~cm}^{-1}$ (ref. 46) (Fig. 1a and b; spectra of other samples are presented in ESI, Fig. S1 $\dagger$ ). The ester bond is cleaved due to the highly alkaline conditions during cationization, resulting in a hydrolysis reaction in the presence of water. ${ }^{47}$ On the other hand, the carbon-nitrogen bond originated from a tertiary amine group of GTAC. In addition, broadening of the peak in the $\mathrm{OH}-$ region (around $3300 \mathrm{~cm}^{-1}$ ) and the water peak around $1650 \mathrm{~cm}^{-1}$ were observed, indicating that the chemical modification altered the hydrogen bonding pattern and the water uptake of the wood. The increased water uptake was later confirmed by TG analysis.

\section{Nanofibrillation of cationic wood}

The production of CWNFs was achieved by the mechanical disintegration of the water suspension of cationic wood with a microfluidizer. All of the samples passed through the microfluidizer without blocking its narrow chambers to produce very low viscosity, yellow suspensions (Fig. S2†). Previously, WNFs with a gel-like appearance have been obtained by sulfation with reactive DESs. ${ }^{\mathbf{4 8 , 4 9}}$ Sulfate groups are more hydrophilic compared to tertiary amine groups introduced into wood in the current study ${ }^{50}$ and the sulfated WNFs exhibited significantly higher charge density compared to CWNFs produced here, both contributing to their high viscosity values.

Generally, the viscosities of the nanofibers produced from high lignin-containing starting materials are lower compared to those obtained from bleached (lignin-free) cellulose. ${ }^{19}$ Low viscosities can originate from the lower degree of hydrophilicity of lignin, decreasing the interaction between WNFs and water (i.e. swelling) when compared to the corresponding CNFs. It should be noted that although CNFs with high viscosity can be highly desirable, for example when used as a rheology modifier, ${ }^{51}$ the low viscosity of WNFs can also be beneficial in the preparation of film-forming solution, as the entrapped air bubbles are more easily removed from low viscosity samples. In addition, low viscosity might enable the production of CWNFs with a high solid content, for example, using a twin-screw extruder. ${ }^{52}$

TEM analysis showed that cationic wood disintegrated into individual nanofibers with a width of approximately $5 \mathrm{~nm}$ (Table 1 and Fig. 2). This measurement is close to that of elementary fibrils (width of $3.5 \mathrm{~nm}$ ) and similar to the values reported for the CNFs produced using bleached cellulose pulp. ${ }^{36,53-56}$ CWNFs varied from micrometer-long nanofibers to shorter, 200-300 nanometer long CNC-like particles. Some larger particles with a width of a few hundred nanometers were observed (Fig. 2b). All the samples also contained high amounts of coarse nanosized particles, which can easily be distinguished from nanofibers that exhibited a sharp, needle-like appearance. The coarse nanoparticles are associated with the amorphous materials (lignin and hemicellulose) present in wood. ${ }^{33,48}$ Due to the high yield of CWNFs, it can be assumed that around half of the materials consist of these amorphous nanoparticles. As cellulose and lignin/hemicellulose are present as separated components, CWNFs can be regarded as a composite between these two individual nanoparticles.

Although the average width of all the samples was within the error range, it appears that CWNFs produced using MU and 1,3DMU had a slightly more narrow size distribution (see the ESI for histograms of the width of the samples, Fig. S7 $\dagger$ ) and thus more uniform nanofibers are obtained using either of these two components in a solvent system. The higher charge density of the CWNFs produced with MU and 1,3-DMU might be explained by the slightly smaller side of the nanofibers, which in turn allows for more efficient interaction between the polymeric titrant used in polyelectrolyte titration when compared to samples produced using urea and EU.
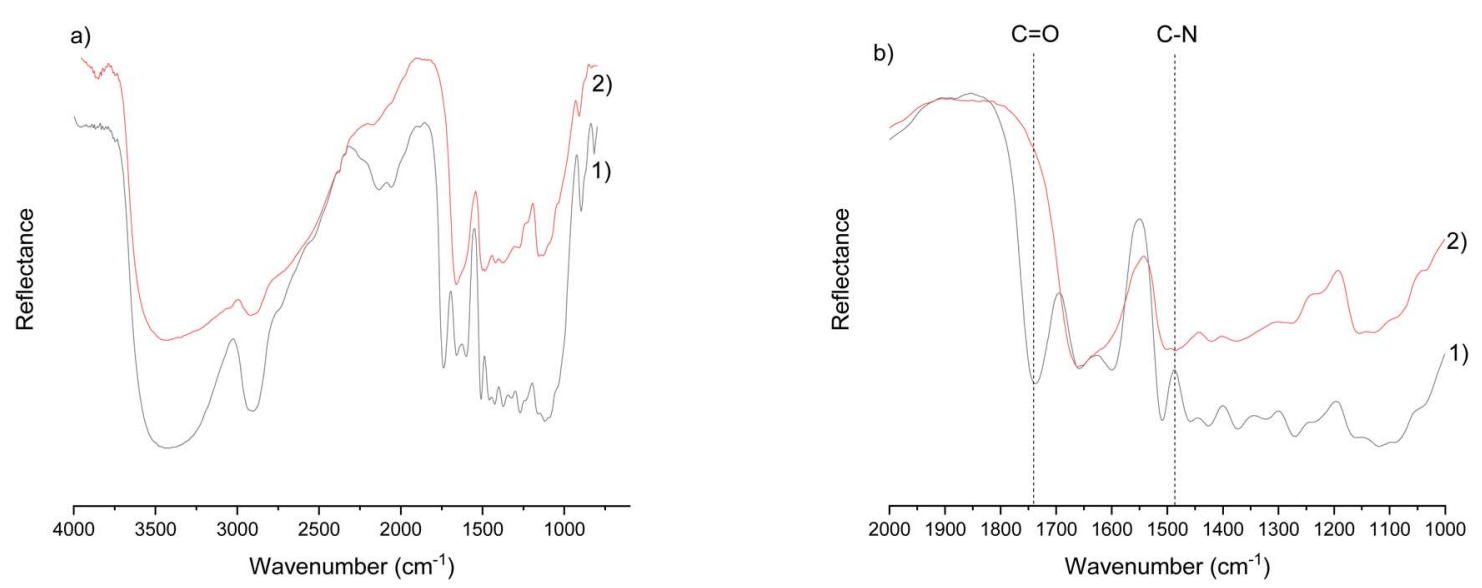

Fig. 1 (a) the DRIFT spectra of wood (1) and cationic wood obtained using urea as carbamide (2), and (b) the fingerprint region of the DRIFT spectra showing the most distinguished differences between the two spectra: the disappearance of the carbonyl peak $(\mathrm{C}=\mathrm{O})$ of the ester bond and the appearance of a carbon-nitrogen peak $(\mathrm{C}-\mathrm{N})$ after chemical modification. 

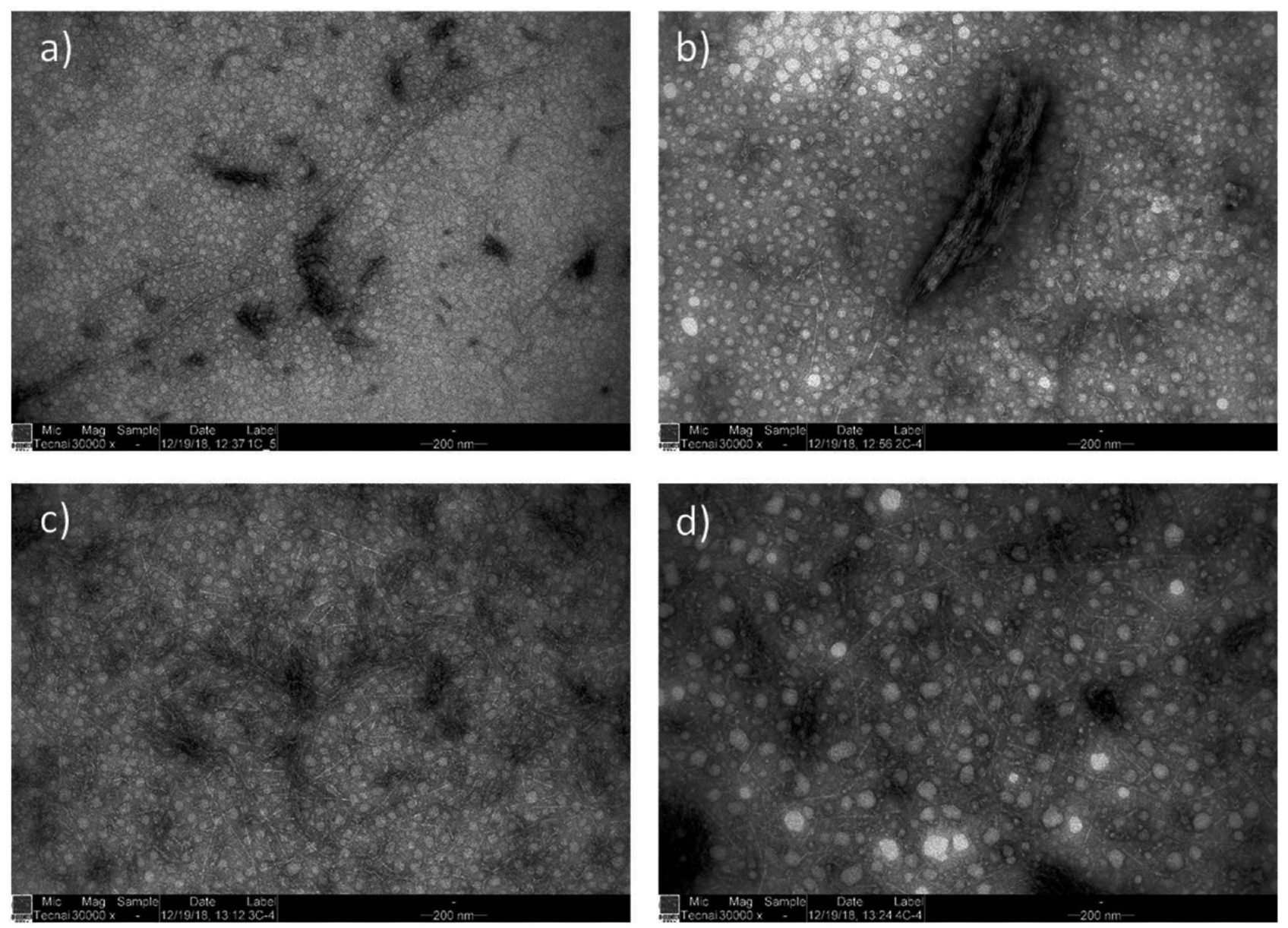

Fig. 2 TEM images of CWNFs obtained using (a) urea, (b) 1,3-DMU, (c) MU, and (d) EU, demonstrating the presence of both short and long nanofibers (a), a small number of bigger, a few hundred nanometer sized aggregates (b) and network like structure (c and d) with a large number of coarse nanoparticles originating from the amorphous components of wood (lignin and hemicelluloses) (see the ESI for high-resolution TEM images, Fig. S3-S6†).

The widths of the CWNFs were in line with previous results obtained from sulfated WNFs produced from sawdus $\mathrm{t}^{48}$ and groundwood pulp ${ }^{49}$ and CWNFs produced from groundwood pulp using DES. ${ }^{33}$ However, compared to CWNFs obtained previously, in the current study, the large particles were present to a lesser extent. Compared to the anionic WNFs produced by succinylation in DES, ${ }^{25}$ the CWNFs produced here have a significantly smaller size distribution.

\section{Cationic wood nanofiber films}

CWNF films were produced using the solvent-casting method, and all the samples produced transparent, yellowish films, with good mechanical robustness (Fig. 3 and S8†). The average thickness of CWNF1, CWNF2, CWNF3, and CWNF4 films was $44,39,57$, and $63 \mu \mathrm{m}$, respectively. When placed directly on top of the background, the underlying image was readily visible (Fig. 3a), whereas when the film was held a few centimeters above the background, haziness could be observed (Fig. 3b), although the background could still be recognized. All the films were also easy to handle and tolerated bending (Fig. 3c).

\section{UV blocking and visible light transparency of the cationic wood nanofiber films}

Transparency is desirable in food packaging due to possibility to see the product, and blocking UV radiation helps to prevent the spoilage of food. UV light can generate singled oxygen that accelerates the oxidation of lipids and degrades antioxidants and vitamins ${ }^{57}$ High visible light transparency and UV-blocking
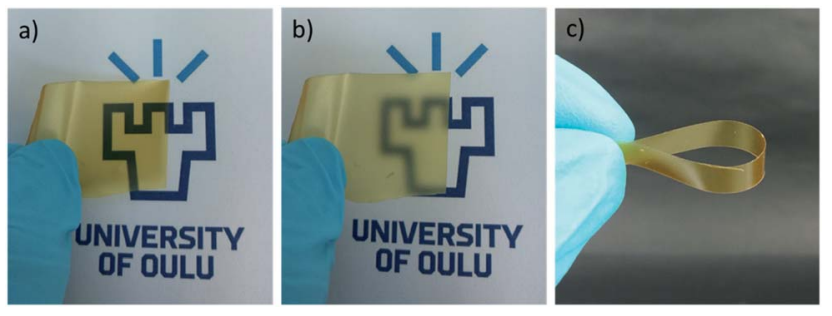

Fig. 3 CWNF film (a) directly on top and (b) held a few centimeters above the background showing good transparence and a slight haziness of the films, and (c) bending of the film to demonstrate good mechanical robustness. 
capabilities are also desirable traits in electronic applications such as solar cells, as many of these devices harvest visible light, and UV light can cause damage to the components, decreasing their lifespan. ${ }^{58}$ Hence, the UV and visible light absorption and transmittance of the CWNF films were investigated.

For all the films tested, strong absorption can be observed in the range of 250-350 nm (Fig. 4a), associated with the presence of lignin (characteristic bands in the UV spectrum of lignin appear at 200-230 $\mathrm{nm}$ and 260-280 $\mathrm{nm}$ (ref. 59)). Due to the strong absorption, the transmittance of UV light $(<400 \mathrm{~nm})$ was practically zero in all the films (Fig. 4b), showing that CWNF films are excellent UV barrier materials. Moderate absorption at the low end of the visible light spectrum explains the intense yellow color, which is visible at 565-590 nm, of the CWNF suspensions and films. Nevertheless, at wavelengths higher than $500 \mathrm{~nm}$, the transmittance values of all the films were above $60 \%$ and around $80 \%$ at $600 \mathrm{~nm}$. The transparency of the CWNF films was higher compared to the previous WNF films obtained from sulfated sawdust, having a transmittance of 41$68 \%$ at a wavelength of $600 \mathrm{~nm} .{ }^{48} \mathrm{UV}$ blocking films (almost zero transparency below $400 \mathrm{~nm}$ ) similar to the CWNF films have previously been produced by mixing CNCs with isolated lignin
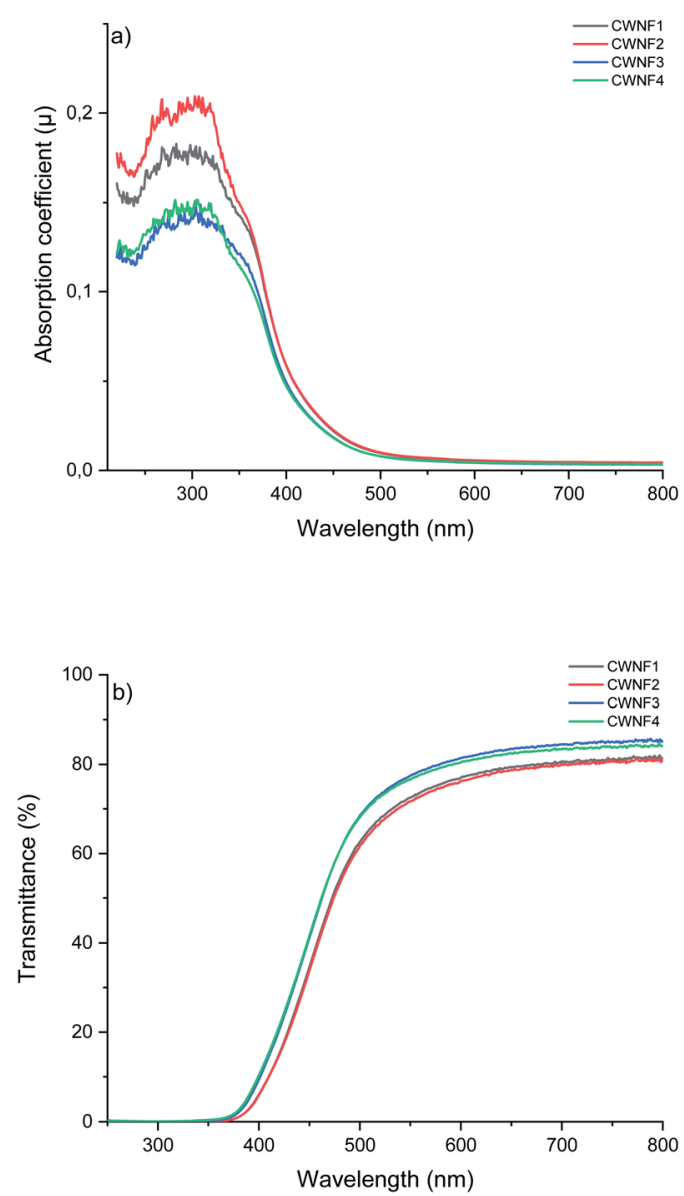

Fig. 4 UV and visible light (a) absorption coefficient and (b) transmittance of CWNF films, showing strong absorption behavior in the UV region $(<400 \mathrm{~nm})$ and high transparency in the visible light region (380-760 nm (ref. 61)).
(10 wt \% lignin content); however, their visible light transmittance was around $20 \%$ and $60 \%$ at wavelengths of 500 and $600 \mathrm{~nm}$, respectively. ${ }^{15}$ Slightly higher visible light transparency compared to the current study has been reported with a coating of CNCs and organosolv lignin, although complete UV blocking was not achieved. ${ }^{16}$ Also, the visible light transmittance of CWNF films is higher compared to the cationic CNF film studied previously. ${ }^{60}$

\section{Oxygen barrier properties of the cationic wood nanofiber films}

As stated before, oxygen is one of the major causes of food spoilage due to its high reactivity. ${ }^{62}$ The results presented in Table 2 indicate that at an $\mathrm{RH}$ of $50 \%$, the oxygen barrier properties (OP values) of CWNF films can be described either as high $\left(\leq 400 \mathrm{~cm}^{3} \mu \mathrm{m}\left(\mathrm{m}^{2} \mathrm{~d} \mathrm{~atm}\right)^{-1}\right)$ or medium (400-4000 $\mathrm{cm}^{3}$ $\left.\mu \mathrm{m}\left(\mathrm{m}^{2} \mathrm{~d} \text { atm }\right)^{-1}\right){ }^{63}$ The results indicate that CWNFs are significantly better oxygen barriers than the hydrophobic synthetic polymers used in packaging materials. ${ }^{63}$ Nevertheless, their OP values are higher compared to efficient oxygen barriers, such as polyvinylidene chloride $\left(10-300 \mathrm{~cm}^{3} \mu \mathrm{m}\left(\mathrm{m}^{2} \mathrm{~d} \mathrm{~atm}\right)^{-1}\right)^{64}$ and films produced from CNFs at an $\mathrm{RH}$ of $50 \%$. For example, OP values of $12,{ }^{55} 35,{ }^{65}$ and 37 (ref. 66) $\mathrm{cm}^{3} \mu \mathrm{m}\left(\mathrm{m}^{2} \mathrm{~d} \text { atm) }\right)^{-1}$ have been reported with anionic CNF films. On the other hand, the OP values of CWNF films at 50\% RH are lower compared to other polysaccharides such as amylose and amylopectin (709 and $1418 \mathrm{~cm}^{3} \mu \mathrm{m}\left(\mathrm{m}^{2} \mathrm{~d} \text { atm }\right)^{-1}$, respectively), ${ }^{67}$ and close to the OP values of cellophane, measured at $0 \% \mathrm{RH}^{63}$

The powerful oxygen barrier properties of CNFs and many synthetic films originate from their strong polar characteristics as well as their crystallinity. ${ }^{63}$ Due to polarity, films have reduced interaction between non-polar oxygen atoms, decreasing the oxygen solubility, and the crystalline structure creates a torturous path, hindering the diffusion. Polarity increases the water adsorption, resulting in the swelling of the film structure, thus allowing oxygen to permeate through films more readily when humidity is increased. The most dramatic increase is usually observed at an RH of $65 \%$ and higher. For example, in the case of carboxymethylated CNF films, the OP values increased from $0.061 \mathrm{~cm}^{3} \mu \mathrm{m}\left(\mathrm{m}^{2} \mathrm{~d} \text { atm }\right)^{-1}$ measured at $0 \%$ to $37-86$ and $3617 \mathrm{~cm}^{3} \mu \mathrm{m}\left(\mathrm{m}^{2} \mathrm{~d} \text { atm }\right)^{-1}$ when the RH was increased to 50 and $80 \%$, respectively. ${ }^{66}$ In the case of the film produced from bacterial CNCs, the OP values increased from 6.12 to $52-264 \mathrm{~cm}^{3} \mu \mathrm{m}\left(\mathrm{m}^{2} \mathrm{~d} \mathrm{~atm}\right)^{-1}$, when the RH increased from 0 to $80 \%$.

The OP values of CWNF films at an RH of $92 \%$ were around 2000-3000 $\mathrm{cm}^{3} \mu \mathrm{m}\left(\mathrm{m}^{2} \mathrm{~d} \text { atm }\right)^{-1}$, thus still being a medium oxygen barrier. ${ }^{63}$ The barrier properties of CWNF films at elevated humidity are in the range of polyethylene terephthalate (1000-5000 $\left.\mathrm{cm}^{3} \mu \mathrm{m}\left(\mathrm{m}^{2} \mathrm{~d} \text { atm }\right)^{-1}\right)$ and over 20 times lower compared to polypropylene and polyethylene. At an $\mathrm{RH}$ of $96 \%$, around two times higher OP values compared to CWNFs were obtained for CNF films produced using a two hour hot-pressing method, whereas by wax dip coating, similar barrier properties compared to CWNFs could be obtained (OP value of $1723 \mathrm{~cm}^{3}$ $\mu \mathrm{m}\left(\mathrm{m}^{2} \mathrm{~d} \text { atm }\right)^{-1}$ at $\left.97 \%\right) .{ }^{68}$ For cellophane ( $\mathrm{RH}$ of $\left.95 \%\right)$ and chitosan (RH of 93\%), an OP value of 25470 and $92477 \mathrm{~cm}^{3} \mu \mathrm{m}$ 


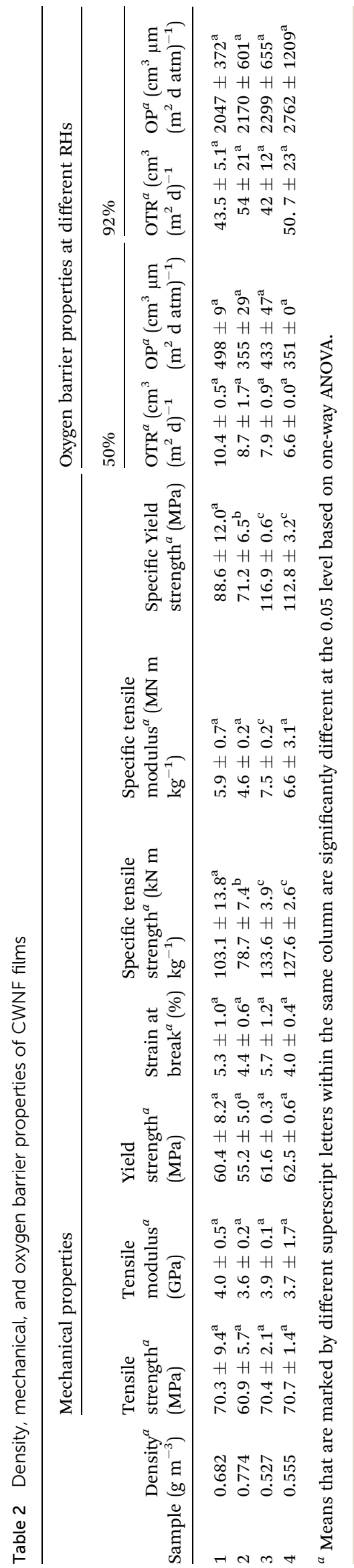

$\left(\mathrm{m}^{2} \mathrm{~d} \text { atm }\right)^{-1}$, respectively, has been reported, ${ }^{63}$ being notably higher when compared to CWNF films. Therefore, at an elevated RH, CWNF films exhibit oxygen barrier properties on par or significantly better when compared with many other biomassbased films and synthetic packaging polymers.

Lignin is a less polar component in comparison to cellulose and hemicellulose and is thus proposed as a valuable component to improve the hydrophobicity of WNF films. The effects of lignin have previously been shown in contact angle measurement $^{19}$ and water absorption ${ }^{18}$ and in improved strength properties at elevated humidity and in a wetted state. ${ }^{69}$ Contradictory results have also been reported, highlighting the effect of its morphology, and other possible factors, on the hydrophobicity of WNF films. In addition, the presence of lignin has also been shown to improve the oxygen barrier properties of WNFs at an $\mathrm{RH}$ of $50 \%$, whereas the opposite effect was observed at higher humidity. ${ }^{18}$ Although the exact lignin content of CWNFs was not determined due to the possible chemical modification of lignin, high yield from the cationic wood indicates that most of the lignin was preserved, and the lignin content in CWNF films is around $24 \mathrm{wt} \%$. The TEM images indicated that both lignin and hemicellulose nanoparticles and nanofibrillated cellulose fibers were relatively homogenously distributed in CWNFs. The homogenous distribution is further supported by the high transmittance of the films, as the presence of large aggregates can decrease light transmittance. Therefore, as previously stated, CWNFs can be described as a composite material, in which oxygen barrier properties are the result of a combination of the individual components. Cellulose and hemicellulose are hydrophilic components which produce effective oxygen barrier properties at low humidity, whereas the presence of lignin reduces swelling of the film structure at elevated humidity. However, less polar lignin slightly decreased the overall oxygen barrier properties due to the higher interaction between oxygen and lignin compared to cellulose. Due to the effective oxygen barrier properties, CWNFs could be potentially used successfully for food packaging. For applications that require extremely high oxygen barriers, such as solar cells, the oxygen barrier properties of CWNFs are too low to be effective. Nevertheless, CWNFs could be used as a UV-blocking layer in laminated structures, where they could also provide a supportive oxygen barrier after the hydrophobic moisture barrier and before the actual oxygen barrier (e.g. poly(vinyl alcohol) ${ }^{70}$ ).

\section{Mechanical properties of the cationic wood nanofiber films}

The mechanical properties of the CWNF films are presented in Table 2. The mean tensile strength of the films varied in between 60 and $71 \mathrm{MPa}$. The differences of means, however, were statistically insignificant at the 0.05 level, as determined by ANOVA analysis. The tensile modulus values were also in the same range for all films (around $4 \mathrm{GPa}$ ). The results obtained here are similar to the ones previously reported for sulfated WNFs produced from sawdust. However, it should be noted that in a previous study, sulfated WNF films exhibited non-yielding characteristics, whereas in the case of CWNF films, yielding was observed and the yield strength of the films was close to $60 \mathrm{MPa}$ 
(see the ESI $\uparrow$ for an example of stress-strain curves). Yielding is a typical property of cellulosic nanofiber films, indicating the point at which nanofibers begin to slip, causing permanent damage to the film structure (i.e. irreversible straining). In the case of CNF films, the yield point is followed by a strong strainhardening tendency, that is, the ultimate tensile strength is generally significantly higher compared to the yield strength. For example, CNF films with similar strain compared to these CWNFs showed a yield strength of $84 \mathrm{MPa}$, approximately $20 \mathrm{MPa}$ higher in comparison. ${ }^{71}$ On the other hand, the ultimate tensile strength of CNFs was over two times higher compared to CWNF films. The strain-hardening effect is likely due to the straightening and alignment of the long and curved nanofibers. $^{72}$ The CWNF contains somewhat round and coarsely shaped nanoparticles, originating from lignin and hemicellulose, that do not align (or are poorly aligned); therefore the strain-hardening of the CWNFs is minimal compared to CNF films. A similar behaviour is observed in CNF composites. ${ }^{73,74}$ The strain-hardening of CNWFs is also strongly associated with the reorganization of the hydrogen bonding network under the strain. ${ }^{75}$ In the case of WNFs, the presence of lignin might partially block the formation of the hydrogen bonding network, thus decreasing the overall tensile strength and the strainhardening.

The density of the CWNF films was lower when compared to the WNF films produced previously, which typically have reported densities of $1-1.5 \mathrm{~g} \mathrm{~m}^{-3} \cdot{ }^{\mathbf{1 8 , 1 9 , 7 6}}$ In a previous study, films are produced using filtration methods that are usually followed by vacuum or hot press-drying at an elevated temperature, which can result in the production of denser films when compared to the solvent-casting method used in this study. Previously, similar densities to the CWNF films $\left(0.5\right.$ and $\left.0.8 \mathrm{~g} \mathrm{~m}^{-3}\right)$ were obtained by the solvent-casting of WNFs produced using homogenization. ${ }^{21}$ To examine the differences in the density, the specific tensile strengths, modulus, and yield were calculated. Except for CWNF 2, the specific tensile strengths were over $100 \mathrm{kN} \mathrm{m} \mathrm{kg}^{-1}$, the highest being $134 \mathrm{kN} \mathrm{m} \mathrm{kg}^{-1}$ for the film produced using MU. The specific tensile strength of CNWs is close to the average tensile strength of CNF films reported in the literature. For example, values of $127 \mathrm{kN}$ $\mathrm{m} \mathrm{kg}^{-1}$ and $160 \mathrm{kN} \mathrm{m} \mathrm{kg}^{-1}$ have been reported for films produced with Masuko ground ${ }^{77}$ and TEMPO-oxidized CNFs. ${ }^{78}$ Nevertheless, it should be noted that a specific tensile strength of $268 \mathrm{kN} \mathrm{m} \mathrm{kg}^{-1}$ has previously been obtained using TEMPO-oxidation. ${ }^{79}$ For WNFs with a high lignin content $(>20 \%)$, specific tensile strengths of $79,{ }^{19} 83,{ }^{25}$ and 90 (ref. 76) $\mathrm{kN} \mathrm{m} \mathrm{kg}^{-1}$ have been obtained.

Therefore, it can be concluded that the mechanical properties of the CWNF films are on par with those of the state-of-theart lignocellulose nanomaterials. In addition, the CWNF films also outperform many synthetic packaging materials, such as polyethylene, propylene and poly(vinyl chloride) having tensile strength in the range of 22.1-31.0, 31.0-41.4 and 40.7-51.7 MPa, respectively. ${ }^{80}$ As stated above, filtration-pressing methods can be used to produce CNF and WNF films with higher density, thus improving the tensile properties. In addition, it has been shown that by using a high temperature during drying, lignin can be softened, resulting in the filling of voids in the nanofiber network. ${ }^{19,20}$ Consequently, hot-pressing can increase the mechanical properties of the films. However, filtration is usually done using a polyvinylidene fluoride membrane with a small anionic surface charge, making the peeling of the cationically charged films from the membrane cumbersome, due to their electrostatic attraction to the membrane. Therefore, alternative membrane materials are recommended for this purpose. However, the strong electrostatic adhesion of CWNFs to surfaces could be used in coatings or in the fabrication of materials with interfacial nanoparticle complexation. ${ }^{\mathbf{8 1}}$

\section{Antimicrobial properties of the cationic wood nanofiber films}

Food spoilage due to microbial growth causes serious health and safety issues due to toxicity. To improve the quality, safety, and shelf life of food products, developing active packaging materials capable of reducing the growth of food pathogens is a possible solution. ${ }^{82}$ In addition to food packaging, antimicrobial properties are also desirable for medical packaging to avoid microbial infections and promote sterilization..$^{\mathbf{3}}$ Here, the film produced using $1,3-$ DMU as the carbamide component of the solvent was investigated as a model film for anti-microbial properties. A narrow inhibition zone around the sample was observed in E. coli and S. aureus, indicating that the CWNF film has certain antimicrobial properties (Fig. 5). In addition, no bacteria were observed to grow on the film, demonstrating strong bacterial anti-adhesive properties. ${ }^{84}$ Previous studies of PVA-composite films containing cationic CNFs showed no inhibition zone in disk testing, but the bacteria did not grow on top nor under the film. ${ }^{36}$ The lack of an inhibition zone was associated with the immobilization of cationic CNFs (as an antimicrobial agent) in films, resulting in the death of the bacteria in direct contact with the film. Our control test with the sulfated WNFs also showed no inhibition zone (Fig. S10 and S11†). Therefore, it seems that a small portion of the CWNF film leaches out of the film structure, causing the anti-bacterial effect around the film. It is possible that amorphous nanoparticles originating from lignin and hemicellulose might not be tightly bound to the film. This may be due to the cationization of lignin and hemicellulose, which then act as antimicrobial agents. However, the inhibition zone is significantly smaller compared to, for example, bacterial nanocellulose films loaded with silver nanoparticles ${ }^{85}$ and curcumin, ${ }^{86}$ where silver ions or small molecular curcumin are easily released from the film. This minimal leaching effect of the CWNF films can be desirable in packaging applications, as leaching of the chemicals (here chemically modified wood components) has to be limited. Therefore, further studies should be conducted to identify which components, if any, are actually leaching and whether they have any toxic effects on animals.

\section{Thermal properties of the cationic wood nanofiber films}

TGA and DTG curves presented in Fig. $6 \mathrm{a}$ and $\mathrm{b}$ indicate that CWNFs exhibit a different thermal degradation behavior compared to sawdust. Under dynamic air (i.e. presence of oxygen), sawdust showed a bimodal mass loss curve. The onset temperature for the first degradation step was around $270{ }^{\circ} \mathrm{C}$ and the highest mass-loss rate was at $314{ }^{\circ} \mathrm{C}$. The second peak of the mass-loss rate was observed at a temperature of $349^{\circ} \mathrm{C}$. The first degradation phase is associated with the degradation 

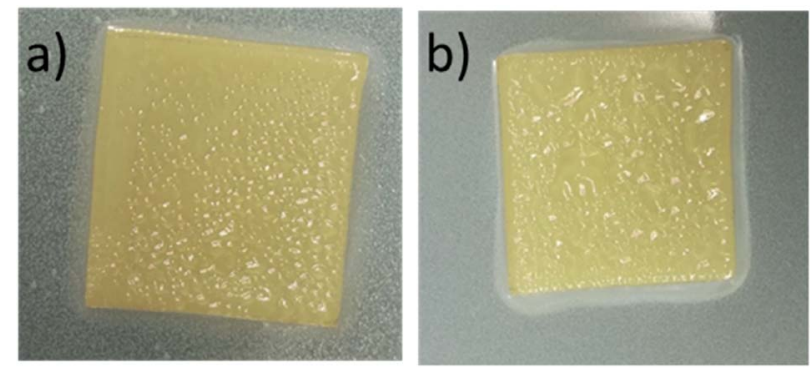

Fig. 5 Photograph of the antimicrobial performance of the CWNF film against (a) E. coli and (b) S. aureus. Narrow inhibition zones can be observed in the light area around the film.
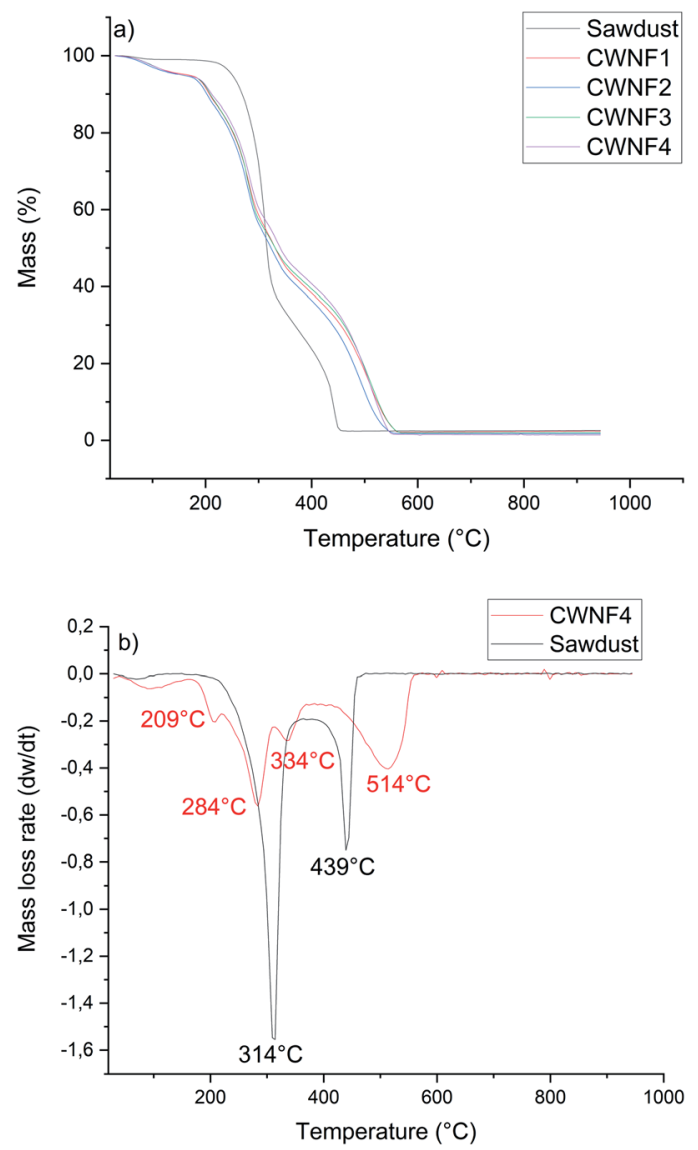

Fig. 6 (a) TGA curves of original sawdust and CWNF films and (b) DTG curve of the CWNF4 film with original sawdust.

of aliphatic components, that is, hemicellulose and cellulose and the first thermal degradation step of lignin. ${ }^{87}$ The second mass-loss peak, starting around $400{ }^{\circ} \mathrm{C}$, is due to the final degradation state of lignin. Due to the presence of different oxygen-bearing chemical groups, lignin has a wider degradation range than hemicellulose and cellulose. ${ }^{88}$

In contrast to the original sample of sawdust, several degradation steps were observed for CWNFs. The first significant difference between the TGA curves of CWNFs and sawdust can be seen at temperatures between 30 and $170{ }^{\circ} \mathrm{C}$. The mass loss in the low temperature range can be attributed to the loss of adsorbed water. ${ }^{89,90}$ For the sawdust, only about $1 \%$ of mass was lost before the first degradation step, whereas for the CWNFs, around $5 \%$ of mass was lost as water. Differing mass loss at low temperatures indicates that the hydrophilicity of sawdust increased during the CWNF production. The onset temperature of degradation for the CWNFs was observed to be around $200{ }^{\circ} \mathrm{C}$, which is around $70{ }^{\circ} \mathrm{C}$ lower in comparison to pure sawdust. The first degradation step, associated with the degradation of the labile quaternary ammonium groups ${ }^{91,92}$ of CWNFs, shows a maximum mass-loss rate at $209{ }^{\circ} \mathrm{C}$. The decomposition of quaternary ammonium groups is related to the formation of volatile components, such as $\left(\mathrm{NCH}_{2}\left(\mathrm{CH}_{3}\right)_{2}\right),{ }^{93}$ either by reverse Menschutkin decomposition or Hofmann elimination. $^{94}$

After the degradation peak of quaternary ammonium groups, two separated mass-loss rate peaks were observed at 284 and $334{ }^{\circ} \mathrm{C}$, and the first degradation step of sawdust was observed in between these peaks. The final degradation step of CWNFs begins around $410^{\circ} \mathrm{C}$, which is slightly higher than that of the sawdust $\left(400^{\circ} \mathrm{C}\right)$. The highest mass-loss rate of the final degradation step was observed at significantly higher temperature for CWNFs $\left(514^{\circ} \mathrm{C}\right)$ than that of the sawdust $\left(439^{\circ} \mathrm{C}\right)$.

The multiple degradation steps in the TGA curve of CWNFs could indicate the separation of wood constituents as more individualized components from the original lignin-hemicellulose-cellulose complex. Hemicellulose is described as a short-chain polymer with the lowest thermal stability among the main wood components. ${ }^{95}$ Therefore, it can be assumed that the degradation of hemicelluloses is observed during the second step, after the degradation of quaternary ammonium groups, in CWNFs. The second step might also be the degradation point for the low crystalline parts of cellulose ${ }^{96}$ generated during the CWNF production. The third degradation step could be the degradation point of the individualized cellulose nanofibers, ${ }^{97}$ which were observed in TEM images. It is possible that the final degradation step in the breakdown of lignin requires a higher temperature due to the formation of a protective char layer around the lignin particles, decreasing the heat transfer. The remaining mass at the onset of the final degradation step of CWNFs at $410{ }^{\circ} \mathrm{C}$ was over $40 \%$, whereas in the case of sawdust, the remaining mass was only $22 \%$ at this point.

\section{Conclusions}

TEAOH with carbamide was successfully used to produce high charge density cationic wood with an excellent yield from sawdust without any chemical pre-treatment to remove wood components. CWNFs were then easily obtained from cationic wood by mechanical disintegration. Due to the presence of lignin, the films produced from CWNFs exhibited strong UVblocking properties, and the narrow side-distribution of cellulosic nanofibers facilitated high optical transparency. The effective oxygen barrier properties of CWNF films even at elevated humidity were also attributed to the presence of individualized cellulosic and lignin nanomaterials working synergistically by decreasing oxygen transmission and the swelling of the films, respectively. Furthermore, the films exhibited anti- 
bacterial properties due to their high cationic group content. Therefore, it is proposed that CWNF films could present an environmentally friendly alternative to oil-based plastics currently used in food packaging and flexible electronics.

\section{Conflicts of interest}

There are no conflicts to declare.

\section{Acknowledgements}

We acknowledge Elisa Wirkkala and Dr. Mika Kaakinen for their assistance in the elemental analysis and TEM measurements, respectively. B.Sc. Kalle Kälkäjä is gratefully acknowledged for their contributions to the experiment. J. A. S. would like to thank the Kone Foundation for its financial support. This research was conducted as part of the ARVOPURU project granted by the European Regional Development Fund of the European Union and funded by the Council of Oulu Region, HaSa Oy, Junnikkala Oy, Keitele Forest Oy, Kuhmo Oy, Pölkky Oy and Westas Group Oy.

\section{Notes and references}

1 R. C. Thompson, C. J. Moore, F. S. vom Saal and S. H. Swan, Philos. Trans. R. Soc., B, 2009, 364, 2153-2166.

2 J. Hopewell, R. Dvorak and E. Kosior, Philos. Trans. R. Soc., B, 2009, 364, 2115-2126.

3 J. M. Garcia and M. L. Robertson, Science, 2017, 358, 870872.

4 B. Geueke, K. Groh and J. Muncke, J. Cleaner Prod., 2018, 193, 491-505.

5 K. J. Groh, T. Backhaus, B. Carney-Almroth, B. Geueke, P. A. Inostroza, A. Lennquist, H. A. Leslie, M. Maffini, D. Slunge, L. Trasande, A. M. Warhurst and J. Muncke, Sci. Total Environ., 2019, 651, 3253-3268.

6 V. Siracusa, P. Rocculi, S. Romani and M. D. Rosa, Trends Food Sci. Technol., 2008, 19, 634-643.

7 T. P. Kainulainen, J. A. Sirviö, J. Sethi, T. I. Hukka and J. P. Heiskanen, Macromolecules, 2018, 51, 1822-1829.

8 S.-A. Park, Y. Eom, H. Jeon, J. M. Koo, E. S. Lee, J. Jegal, S. Y. Hwang, D. X. Oh and J. Park, Green Chem., 2019, 21, 5212-5221.

9 J. Baruah, B. K. Nath, R. Sharma, S. Kumar, R. C. Deka, D. C. Baruah and E. Kalita, Front. Energy Res., 2018, 6, 1-19.

10 A. Duval and M. Lawoko, React. Funct. Polym., 2014, 85, 7896.

11 B. M. Upton and A. M. Kasko, Chem. Rev., 2016, 116, 22752306.

12 E. M. Zadeh, S. F. O'Keefe and Y.-T. Kim, ACS Omega, 2018, 3, 7388-7398.

13 H. Sadeghifar, R. Venditti, J. Jur, R. E. Gorga and J. J. Pawlak, ACS Sustain. Chem. Eng., 2017, 5, 625-631.

14 A. Brhoum, A. Dufresne, T. Öhlund and P. Samyn, Nanoscale, 2017, 9, 15181-15205.

15 M. Parit, P. Saha, V. A. Davis and Z. Jiang, ACS Omega, 2018, 3, 10679-10691.
16 A. Hambardzumyan, L. Foulon, B. Chabbert and V. AguiéBéghin, Biomacromolecules, 2012, 13, 4081-4088.

17 M. Farooq, T. Zou, G. Riviere, M. H. Sipponen and M. Österberg, Biomacromolecules, 2019, 20, 693-704.

18 E. Rojo, M. S. Peresin, W. W. Sampson, I. C. Hoeger, J. Vartiainen, J. Laine and O. J. Rojas, Green Chem., 2015, 17, 1853-1866.

19 M. Visanko, J. A. Sirviö, P. Piltonen, R. Sliz, H. Liimatainen and M. Illikainen, Cellulose, 2017, 24, 4173-4187.

20 M. Herrera, K. Thitiwutthisakul, X. Yang, P. Rujitanaroj, R. Rojas and L. Berglund, Cellulose, 2018, 25, 3121-3133.

21 K. L. Spence, R. A. Venditti, Y. Habibi, O. J. Rojas and J. J. Pawlak, Bioresour. Technol., 2010, 101, 5961-5968.

22 I. Solala, A. Volperts, A. Andersone, T. Dizhbite, N. MironovaUlmane, A. Vehniäinen, J. Pere and T. Vuorinen, Holzforschung, 2012, 66, 477-483.

23 M. Hassan, L. Berglund, E. Hassan, R. Abou-Zeid and K. Oksman, Cellulose, 2018, 25, 2939-2953.

24 S. Iwamoto and T. Endo, ACS Macro Lett., 2015, 4, 80-83.

25 J. A. Sirviö and M. Visanko, J. Mater. Chem. A, 2017, 5, 2182821835.

26 J. A. Sirviö and M. Visanko, J. Hazard. Mater., 2020, 383, 121174.

27 N. Singh and K. Prasad, Green Chem., 2019, 21, 3328-3333.

28 W. H. Evans, E. J. David and S. J. Patterson, Water Res., 1973, 7, 975-985.

29 M. Roman and W. T. Winter, Biomacromolecules, 2004, 5, 1671-1677.

30 H. J. Prado and M. C. Matulewicz, Eur. Polym. J., 2014, 52, 5375.

31 R. Wahlström, A. Kalliola, J. Heikkinen, H. Kyllönen and T. Tamminen, Ind. Crops Prod., 2017, 104, 188-194.

32 J. A. Sirviö and J. P. Heiskanen, Cellulose, 2020, 27, 19331950.

33 J. A. Sirviö, Carbohydr. Polym., 2018, 198, 34-40.

34 F. Rol, M. N. Belgacem, A. Gandini and J. Bras, Prog. Polym. Sci., 2019, 88, 241-264.

35 N. Odabas, H. Amer, M. Bacher, U. Henniges, A. Potthast and T. Rosenau, ACS Sustain. Chem. Eng., 2016, 4, 2295-2301.

36 A. Chaker and S. Boufi, Carbohydr. Polym., 2015, 131, 224232.

37 A. Olszewska, P. Eronen, L.-S. Johansson, J.-M. Malho, M. Ankerfors, T. Lindström, J. Ruokolainen, J. Laine and M. Österberg, Cellulose, 2011, 18, 1213.

38 K. Littunen, J. Snoei de Castro, A. Samoylenko, Q. Xu, S. Quaggin, S. Vainio and J. Seppälä, Eur. Polym. J., 2016, 75, 116-124.

39 A. Pei, N. Butchosa, L. A. Berglund and Q. Zhou, Soft Matter, 2013, 9, 2047-2055.

40 F. Rol, S. Saini, V. Meyer, M. Petit-Conil and J. Bras, Ind. Crops Prod., 2019, 137, 81-88.

41 T. T. T. Ho, T. Zimmermann, R. Hauert and W. Caseri, Cellulose, 2011, 18, 1391-1406.

42 H. Liimatainen, T. Suopajärvi, J. Sirviö, O. Hormi and J. Niinimäki, Carbohydr. Polym., 2014, 103, 187-192.

43 T. Suopajärvi, J. A. Sirviö and H. Liimatainen, J. Environ. Chem. Eng., 2017, 5, 86-92. 
44 T. Selkälä, T. Suopajärvi, J. A. Sirviö, T. Luukkonen, P. Kinnunen, K. I. Kling, J. B. Wagner and H. Liimatainen, Chem. Eng. J., 2019, 374, 1013-1024.

45 M. Jonoobi, K. O. Niska, J. Harun and M. Misra, BioResources, 2009, 4, 626-639.

46 Y. Wang and W. Xie, Carbohydr. Polym., 2010, 80, 1172-1177.

47 N. Giummarella, Y. Pu, A. J. Ragauskas and M. Lawoko, Green Chem., 2019, 21, 1573-1595.

48 P. Li, J. A. Sirviö, S. Hong, A. Ämmälä and H. Liimatainen, Chem. Eng. J., 2019, 375, 122050.

49 J. A. Sirviö and M. Visanko, Biomacromolecules, 2019, 20, 2413-2420.

50 J. T. Davies, Proceedings of the Second International Congress on Surface Activity, Butterworth, London, 1957, vol. 1, p. 426.

51 E. Jiang, N. Amiralian, M. Maghe, B. Laycock, E. McFarland, B. Fox, D. J. Martin and P. K. Annamalai, ACS Sustain. Chem. Eng., 2017, 5, 3296-3304.

52 F. Rol, B. Karakashov, O. Nechyporchuk, M. Terrien, V. Meyer, A. Dufresne, M. N. Belgacem and J. Bras, ACS Sustain. Chem. Eng., 2017, 5, 6524-6531.

53 P. Li, J. A. Sirviö, B. Asante and H. Liimatainen, Carbohydr. Polym., 2018, 199, 219-227.

54 A. Isogai, T. Saito and H. Fukuzumi, Nanoscale, 2011, 3, 71-85. 55 J. A. Sirviö, A. Kolehmainen, M. Visanko, H. Liimatainen, J. Niinimäki and O. E. O. Hormi, ACS Appl. Mater. Interfaces, 2014, 6, 14384-14390.

56 A. Naderi, A. Koschella, T. Heinze, K.-C. Shih, M.-P. Nieh, A. Pfeifer, C.-C. Chang and J. Erlandsson, Carbohydr. Polym., 2017, 169, 515-523.

57 V. Goudarzi, I. Shahabi-Ghahfarrokhi and A. BabaeiGhazvini, Int. J. Biol. Macromol., 2017, 95, 306-313.

58 P. Cheng and X. Zhan, Chem. Soc. Rev., 2016, 45, 2544-2582.

59 R. A. Lee, C. Bédard, V. Berberi, R. Beauchet and J.-M. Lavoie, Bioresour. Technol., 2013, 144, 658-663.

60 P. Li, J. A. Sirviö, A. Haapala, A. Khakalo and H. Liimatainen, Food Hydrocoll, 2019, 92, 208-217.

61 C. Starr, C. A. Evers and L. Starr, Biology: Concepts and Applications, Thomson, Brooks/Cole, 2006.

62 S.-I. Hong and J. M. Krochta, J. Food Sci., 2003, 68, 224-228.

63 J. Wang, D. J. Gardner, N. M. Stark, D. W. Bousfield, M. Tajvidi and Z. Cai, ACS Sustain. Chem. Eng., 2018, 6, 49-70.

64 J. Lange and Y. Wyser, Packag. Technol. Sci., 2003, 16, 149-158.

65 V. Kumar, R. Bollström, A. Yang, Q. Chen, G. Chen, P. Salminen, D. Bousfield and M. Toivakka, Cellulose, 2014, 21, 3443-3456.

66 C. Aulin, M. Gällstedt and T. Lindström, Cellulose, 2010, 17, 559-574.

67 A. Rindlav-Westling, M. Stading, A.-M. Hermansson and P. Gatenholm, Carbohydr. Polym., 1998, 36, 217-224.

68 M. Österberg, J. Vartiainen, J. Lucenius, U. Hippi, J. Seppälä, R. Serimaa and J. Laine, ACS Appl. Mater. Interfaces, 2013, 5, 4640-4647.

69 J. Sethi, M. Visanko, M. Österberg and J. A. Sirviö, Carbohydr. Polym., 2019, 203, 148-156.

70 J. Gaume, P. Wong-Wah-Chung, A. Rivaton, S. Thérias and J.-L. Gardette, RSC Adv., 2011, 1, 1471-1481.
71 M. Henriksson, L. A. Berglund, P. Isaksson, T. Lindström and T. Nishino, Biomacromolecules, 2008, 9, 1579-1585.

72 H. Sehaqui, S. Morimune, T. Nishino and L. A. Berglund, Biomacromolecules, 2012, 13, 3661-3667.

73 F. Ansari, S. Galland, M. Johansson, C. J. G. Plummer and L. A. Berglund, Compos. Part Appl. Sci. Manuf., 2014, 63, $35-44$.

74 M. Y. Ismail, M. Patanen, J. A. Sirviö, M. Visanko, T. Ohigashi, N. Kosugi, M. Huttula and H. Liimatainen, Carbohydr. Polym., 2019, 218, 87-94.

75 Q. Meng and T. J. Wang, Appl. Mech. Rev., 2019, 71, 040801. 76 A. Ämmälä, O. Laitinen, J. A. Sirviö and H. Liimatainen, Ind. Crops Prod., 2019, 140, 111664.

77 J. Sethi, M. Farooq, S. Sain, M. Sain, J. A. Sirviö, M. Illikainen and K. Oksman, Cellulose, 2018, 25, 259-268.

78 H. Fukuzumi, T. Saito, T. Iwata, Y. Kumamoto and A. Isogai, Biomacromolecules, 2009, 10, 162-165.

79 M. Salajkova, L. Valentini, Q. Zhou and L. A. Berglund, Compos. Sci. Technol., 2013, 87, 103-110.

80 W. D. C. Jr and D. G. Rethwisch, Fundamentals of Materials Science and Engineering: an Integrated Approach, John Wiley \& Sons, 2012.

81 K. Zhang and H. Liimatainen, Small, 2018, 14, 1801937.

82 B. Malhotra, A. Keshwani and H. Kharkwal, Front. Microbiol., 2015, 6, 1-9.

83 D. Sun, M. B. Shahzad, M. Li, G. Wang and D. Xu, Mater. Technol., 2015, 30, B90-B95.

84 J. A. Sirviö, A.-K. Anttila, A. M. Pirttilä, H. Liimatainen, I. Kilpeläinen, J. Niinimäki and O. Hormi, Cellulose, 2014, 1-11.

85 S. Pal, R. Nisi, M. Stoppa and A. Licciulli, ACS Omega, 2017, 2, 3632-3639.

86 M. Khamrai, S. L. Banerjee and P. P. Kundu, Carbohydr. Polym., 2017, 174, 580-590.

87 K. Slopiecka, P. Bartocci and F. Fantozzi, Appl. Energy, 2012, 97, 491-497.

88 Q. Liu, S. Wang, Y. Zheng, Z. Luo and K. Cen, J. Anal. Appl. Pyrolysis, 2008, 82, 170-177.

89 F. Zhang, Z. Pang, C. Dong and Z. Liu, Carbohydr. Polym., 2015, 132, 214-220.

90 J. A. Sirviö, T. Hasa, J. Ahola, H. Liimatainen, J. Niinimäki and O. Hormi, Carbohydr. Polym., 2015, 133, 524-532.

91 G. Li, Y. Fu, Z. Shao, F. Zhang and M. Qin, BioResources, 2015, 10, 7782-7794.

92 P. P. Danilovas, R. Rutkaite and A. Zemaitaitis, Carbohydr. Polym., 2014, 112, 721-728.

93 W. Xie, Z. Gao, W.-P. Pan, D. Hunter, A. Singh and R. Vaia, Chem. Mater., 2001, 13, 2979-2990.

94 S. Sowmiah, V. Srinivasadesikan, M.-C. Tseng and Y.-H. Chu, Molecules, 2009, 14, 3780-3813.

95 T. Sebio-Puñal, S. Naya, J. López-Beceiro, J. Tarrío-Saavedra and R. Artiaga, J. Therm. Anal. Calorim., 2012, 109, 1163-1167.

96 M. Poletto, H. L. Ornaghi and A. J. Zattera, Materials, 2014, 7, 6105-6119.

97 C. Borsoi, M. V. G. Zimmernnam, A. J. Zattera, R. M. C. Santana and C. A. Ferreira, J. Therm. Anal. Calorim., 2016, 126, 1867-1878. 